\title{
Aulas Práticas de Laboratório como Método de Ensino de Genética Molecular
}

\author{
Andressa Monteiro Venturini ${ }^{1 *}$, Leandro Fonseca de Souza ${ }^{1}$, Naissa Maria Silvestre Dias², \\ Claudia Barros Monteiro-Vitorello3, Maria Carolina Quecine ${ }^{3}$ \\ ${ }^{1}$ Laboratório de Biologia Celular e Molecular, Centro de Energia Nuclear na Agricultura, Universidade de São Paulo \\ 2Laboratório de Biogeoquímica Ambiental, Centro de Energia Nuclear na Agricultura, Universidade de São Paulo \\ "Laboratório de Genética de Microrganismos "Prof. João Lúcio de Azevedo", Escola Superior de Agricultura "Luiz de \\ Queiroz", Universidade de São Paulo
}

* Autora para correspondência: aventurini@cena.usp.br

\section{RESUMO}

A genética é considerada uma das mais difíceis ciências para estudantes do ensino superior; assim, diferentes métodos de ensino devem ser utilizados para facilitar o seu processo de ensino-aprendizagem e tornar os alunos os protagonistas de seus saberes. Neste relato, foi avaliado o emprego de aulas práticas de laboratório como método de ensino na disciplina de Genética Molecular por meio das seguintes técnicas avaliativas: quizzes, questionário e observação em sala de aula. O conjunto de dados coletados em uma turma ao longo de um semestre demonstrou que o uso de aulas práticas favoreceu a aprendizagem dos conteúdos e procedimentos da pesquisa científica em genética molecular, além de aumentar a motivação dos alunos e promover o trabalho em grupo.

Palavras-Chave: Processo de Ensino-Aprendizagem; Ensino Superior; Ciências; Protagonismo; Motivação.

\begin{abstract}
Genetics is considered one of the most difficult sciences for undergraduate students, so different teaching methods should be used to facilitate its teaching-learning process and make the students the protagonists of their knowledge. In this report, the use of laboratory practical classes as a teaching method in the Molecular Genetics course was evaluated through the following evaluation techniques: quizzes, questionnaire, and classroom observation. The data collected in a class during one semester demonstrated that the use of practical classes favored the learning of the contents and procedures of the scientific research in molecular genetics, besides increasing students' motivation and promoting group work.
\end{abstract}

Keywords: Teaching-Learning Process; Higher Education; Sciences; Protagonism; Motivation.

\section{Introdução}

A genética molecular é o ramo da genética e da biologia molecular que estuda a estrutura, a organização e a função dos genes em um nível molecular (FULTON, 2008; PIERCE, 2012). Sua aplicação em diversos setores, como medicina, agropecuária e indústria, faz com que esse importante campo esteja presente no cotidiano dos estudantes. Entretanto, o aprendizado de conteúdos de genética é reconhecidamente um dos mais desafiadores para alunos do ensino médio e superior, devido principalmente à sua terminologia específica, ao conteúdo matemático, à natureza abstrata e complexa associada a diferentes níveis de organização biológicos (BAHAR et al., 1999; KNIPPELS, 2002; KNIPPELS et al., 2005), dificuldades também presentes no ensino de genética molecular (DUNCAN \& REISER, 2007).

No processo de ensino-aprendizagem, os métodos de ensino consistem nas atividades desempenhadas pelos docentes para se atingirem objetivos de aprendizagem previamente definidos (MASETTO, 2003). Dentre esses métodos, considera-se o uso de aulas práticas uma parte fundamental do ensino das ciências que, por meio 
do elo entre o domínio das ideias e o domínio dos objetos, propriedades e eventos observáveis, pode favorecer o aprendizado dos estudantes a respeito da ciência em si e de seus conteúdos específicos (MILLAR et al., 2002; MILLAR, 2004). Nesse sentido, o objetivo deste relato foi avaliar o emprego de aulas práticas de laboratório como método de ensino na disciplina de Genética Molecular, sobretudo considerando sua contribuição para a aprendizagem dos conteúdos e procedimentos específicos desse campo, assim como seu papel na motivação dos alunos.

\section{Desenvolvimento}

\section{Contexto}

Os cursos de Engenharia Agronômica e Engenharia Florestal da Escola Superior de Agricultura "Luiz de Queiroz" da Universidade de São Paulo tiveram seus currículos atualizados no ano de 2010 e passaram a integrar Genética Molecular como disciplina obrigatória. Essa inclusão se deu associada ao uso de aulas práticas, com a finalidade de formar profissionais aptos a lidarem com as tecnologias mais recentes em suas áreas de trabalho. No entanto, atividades laboratoriais exigem empenho intenso do docente no seu planejamento; escolha, compra e preparo de materiais; e descarte apropriado de resíduos. Essas demandas, aliadas ao desafio de trabalhar com grande número de alunos em um laboratório, tornam o processo de aprimoramento uma constante necessária.

A disciplina de Genética Molecular é oferecida anualmente em duas horas-aula semanais pelo Departamento de Genética para estudantes de ambos os cursos a partir do seu segundo semestre de ingresso, divididos em oito turmas. O objetivo é apresentar os fundamentos da genética molecular, com ênfase em avanços recentes e na sua aplicação nos setores agropecuário e florestal, através de aulas expositivas e práticas. A disciplina também representa uma oportunidade para os alunos aprenderem mais sobre a pesquisa científica desse campo através do desenvolvimento de projetos e seminários em grupos.

\section{Material e Métodos}

O trabalho foi realizado na turma 06 do ano de 2016, com a participação dos estagiários do Programa de Aperfeiçoamento de Ensino da Universidade de São Paulo (PAE). O plano da disciplina foi composto de nove aulas expositivas e duas aulas práticas de laboratório sobre os temas "Enzimas de restrição, reação em cadeia da polimerase (PCR) e eletroforese em gel de agarose" e "Transformação bacteriana por eletroporação e seleção de clones". Esses temas abrangem metodologias atuais e rotineiras em laboratórios de pesquisa de universidades e empresas, uma demanda considerada essencial pelos docentes da disciplina.

Cada aula prática foi composta pelas seguintes etapas: introdução, apresentação de um problema e conversa com os alunos sobre como resolver esse problema utilizando técnicas da genética molecular; divisão da turma em até quatro grupos de trabalho, com cerca de oito pessoas cada; execução dos protocolos das técnicas previamente definidas; análise, discussão dos resultados e conclusão.

O emprego das aulas práticas na disciplina foi analisado por meio de diferentes técnicas avaliativas. Na semana seguinte a cada prática, foi aplicado um quiz em formato de prova composto por três a seis perguntas discursivas sobre os seus conteúdos, com duração aproximada de dez minutos. No fim do semestre, foi aplicado questionário com perguntas dicotômicas, baseadas em uma escala do tipo Likert e abertas a respeito da percepção dos alunos sobre as aulas. Compunham o questionário estas seis perguntas: (1) "Em outras disciplinas cursadas anteriormente, você participou de aulas práticas de laboratório?"; (2) Em uma escala de 1 ("desgostei muito") a 5 ("gostei muito"), "quanto você gostou das aulas práticas?"; (3) Em uma escala de 1 ("nada importante") a 5 ("muito importante"), "quanto as aulas práticas foram importantes para o entendimento do conteúdo ministrado?"; (4) Em uma escala crescente de 1 ("nada importante") a 5 ("muito importante"), "quanto as aulas práticas foram importantes para o entendimento de como é o dia a dia do cientista 
da área de genética molecular?"; (5) "Na disciplina de Genética Molecular e em outras disciplinas, você gostaria de participar de mais aulas práticas de laboratório?"; (6) "Sugestões e comentários". Por fim, durante todo o semestre, também foi realizada a observação dos alunos em sala de aula.

\section{Resultados}

Foram aplicados dois quizzes sobre os conteúdos previamente abordados em cada uma das aulas práticas. Em uma escala de 0 a 10, a média dos resultados do primeiro quiz, sobre o tema "Enzimas de restrição, reação em cadeia da polimerase (PCR) e eletroforese em gel de agarose", foi de 5,4 $( \pm 1,9)$; e do segundo quiz, sobre "Transformação bacteriana por eletroporação e seleção de clones", $7,1( \pm 1,9)$.

De um total de trinta alunos, 22 responderam ao questionário. Na pergunta 1 , todos os entrevistados (100\%) afirmaram que participaram de aulas práticas anteriormente. Os resultados das perguntas 2, 3 e 4, respondidas em uma escala crescente de 1 a 5, mostraram que cerca de 77\% dos participantes da pesquisa "gostaram" ou "gostaram muito" das referidas aulas, enquanto que seu papel para o entendimento dos conteúdos ministrados e da rotina de trabalho do cientista que atua na área de genética molecular foi considerado "importante" ou "muito importante" para aproximadamente $68 \%$ e $73 \%$ do grupo, respectivamente (Figura 1). Somente cerca de 9\% dos entrevistados classificaram as aulas na pergunta 4 como "nada importantes" ou "pouco importantes". Na pergunta 5, todos os participantes $(100 \%)$ responderam que gostariam de participar de mais aulas semelhantes, nessa ou em outras disciplinas. No campo aberto para sugestões e comentários, duas pessoas sugeriram a divisão da turma em grupos de trabalho menores para propiciar o melhor aproveitamento das atividades de laboratório.

\section{Discussão}

O emprego de atividades práticas tem como principais objetivos: consolidar o aprendizado dos alunos sobre os conteúdos ministrados; aprimorar o seu entendimento sobre a ciência e o método científico; apresentar procedimentos e, consequentemente, desenvolver habilidades técnicas específicas nos estudantes; além de aumentar a motivação da turma e promover o trabalho em grupo (ALLISON, 1995). Os resultados dos conjuntos de dados coletados através dos quizzes, questionário e observação em sala de aula durante um semestre demonstraram o alcance dos objetivos de aprendizagem pretendidos para as aulas práticas de laboratório da disciplina.

O desempenho da turma nos quizzes associado ao seu conceito sobre o papel das aulas práticas no entendimento dos conteúdos evidencia a sua importância no ensino de genética molecular. Em suas respostas, os alunos conseguiram descrever e explicar os procedimentos realizados assim

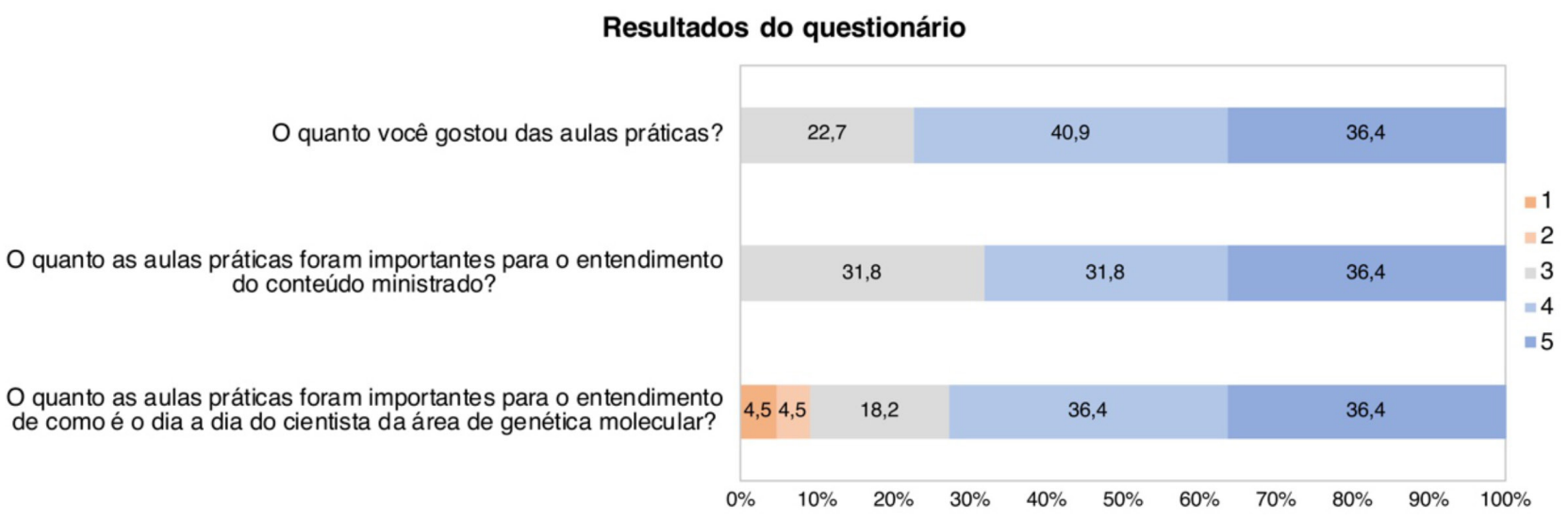

Figura 1 - Percentual das respostas para as perguntas 2, 3 e 4 do questionário, em uma escala crescente de 1 ("desgostei muito" ou "nada importante") a 5 ("gostei muito" ou "muito importante"). 
como discorrer sobre os resultados obtidos, correlacionando-os com conteúdos previamente abordados no semestre. Do mesmo modo, as atividades em laboratório permitiram que a turma fosse apresentada a materiais e equipamentos, os quais foram utilizados para executar técnicas da genética molecular e assim resolver os problemas propostos em aula. Para a maioria dos alunos, as aulas práticas conseguiram elucidar a rotina de trabalho do cientista que atua nessa área, possibilitando um novo olhar sobre esse amplo campo de atuação profissional.

O destaque das aulas práticas como instrumento motivador na disciplina foi igualmente observado. Durante as atividades, os alunos se mostraram interessados e participativos, assim como os resultados do questionário apontaram que a maioria da turma gostou e apresentou vontade de participar de experiências semelhantes. De modo geral, o uso diversificado de métodos de ensino atende às particularidades de cada aluno e faz com que a rotina em sala de aula seja mais dinâmica (MASETTO, 2003). Especialmente, métodos que tornam o ensino dos conteúdos mais interessante e fácil de ser compreendido, assim como o desenvolvimento de aulas em que os estudantes se tornem os protagonistas do processo de ensino-aprendizagem representam importantes formas de motivá-los (JESUS, 2008). Foi também observado que a realização das práticas em grupos de trabalho criou um ambiente cooperativo e de troca de ideias.

Por fim, ressalta-se a importância de as aulas práticas serem organizadas de forma a permitir que o aluno reflita sobre as atividades propostas, extrapolando o simples cumprimento de um determinado protocolo laboratorial; e da mesma forma, seu emprego pode ser ainda mais eficaz se utilizadas para resolver um problema previamente apresentado em aula (MILLAR, 2004), como realizado na disciplina. Nesse sentido, foi considerado que houve melhorias nas aulas em decorrências da metodologia empregada. Contudo, alguns pontos ainda precisam ser aprimorados. $\mathrm{O}$ grande número de alunos por turma impossibilitou a sua realização em grupos de trabalho menores, devido ao custo e ao tempo de preparo dos materiais. Consequentemente, para alguns alunos, as atividades tiveram efeito demonstrativo, ainda que realizadas em laboratório. Isso diverge dos objetivos inicialmente propostos para essas aulas e deve ser reavaliado em semestres posteriores.

\section{Conclusão}

O emprego de aulas práticas de laboratório na disciplina de Genética Molecular contribuiu com a aprendizagem dos seus conteúdos e procedimentos, motivou a turma de alunos, bem como promoveu o protagonismo e o trabalho em grupo. No entanto, novas abordagens se fazem necessárias para reduzir gastos e facilitar o preparo dos materiais, de forma a permitir que mais estudantes executem as atividades. Os resultados obtidos são fundamentais para o constante aprimoramento das aulas práticas da disciplina, assim como dos demais métodos aplicados ao ensino de genética molecular.

\section{Agradecimentos}

Os autores agradecem ao Programa de Aperfeiçoamento de Ensino da Escola Superior de Agricultura "Luiz de Queiroz" da Universidade de São Paulo, à Fundação de Amparo à Pesquisa do Estado de São Paulo (Fapesp, processo n. 2015/13546-7), ao Conselho Nacional de Desenvolvimento Científico e Tecnológico (CNPq, processos n. 140032/2015-0 e 140953/2017-5) e à Coordenação de Aperfeiçoamento de Pessoal de Nível Superior (Capes/Proex).

\section{Referências Bibliográficas}

ALLISON, Iain. "Demonstrating". In: FOSTER, Fred; HOUNSELL, D.; THOMPSON, S. Tutoring and Demonstrating: a Handbook. Edinburgh: Centre for Teaching, Learning and Assessment, The University of Edinburgh in association with the (former) Universities' and Colleges' Staff Development Agency, 1995.

BAHAR, Mehmet; JOHNSTONE, A. H. \& HANSELL, M. H. "Revisiting Learning Difficulties in Biology". Journal of Biological Education, vol. 33, 
n. 2, 1999, pp. 84-86. Disponível em: <https://doi.or $\mathrm{g} / 10.1080 / 00219266.1999 .9655648>$. Acessado em 4 jan. 2018.

DUNCAN, Ravit Golan \& REISER, B. J. "Reasoning across Ontologically Distinct Levels: Students' Understandings of Molecular Genetics". Journal of Research in Science Teaching, vol. 44, n. 7, 2007, pp. 938-959. Disponível em: <https://doi.org/10.1002/ tea.20186>. Acessado em 22 jan. 2018.

FULTON, Janet Elizabeth. "Molecular Genetics in a Modern Poultry Breeding Organization". World's Poultry Science Journal, vol. 64, n. 2, 2008, pp. 171-176. Disponível em: <https://doi.org/10.1017/ S0043933907001778>. Acessado em 11 mar. 2017.

JESUS, Saul Neves de. "Estratégias para Motivar os Alunos". Educaşão, vol. 31, n. 1, 2008, pp. 21-29. Disponível em: <http://revistaseletronicas.pucrs.br/ojs/ index.php/faced/article/view/2753>. Acessado em 21 nov. 2017.

KNIPPELS, Marie-Christine Paulina Josephina. Coping with the Abstract and Complex Nature of Genetics in Biology Education: The Yo-yo Learning and Teaching Strategy. Tese (Doutorado em Science and Mathmatics Education), Universidade de Utrecht, 2002. Disponível em: <https://dspace.library.uu.nl/handle/1874/219>. Acessado em 13 mar. 2017.
; WAARLO, A. J. \& BOERSMA, K. T. "Design Criteria for Learning and Teaching Genetics". Journal of Biological Education, vol. 39, n. 3, 2005, pp. 108-112. Disponível em: <https://doi.org/10.1080/002 19266.2005.9655976>. Acessado em 4 jan. 2018.

MASETTO, Marcos Tarciso. "Técnicas para o Desenvolvimento da Aprendizagem em Aula". In: Competência Pedagógica do Professor Universitário. São Paulo: Summus Editorial, 2003.

MILLAR, Robin. The Role of Practical Work in the Teaching and Learning of Science. Washington, D. C.: High School Science Laboratories: Role and Vision. National Academy of Sciences, 2004. Disponível em: $<$ http://sites.nationalacademies.org/DBASSE/BOSE/ DBASSE_080138>. Acessado em 21 nov. 2017. ; TIBERGHIEN, A. \& LE MARÉCHAL, J. F. "Varieties of Labwork: a Way of Profiling Labwork Tasks". In: PSILLOS, Dimitris \& NIEDDERER, H. Teaching and Learning in the Science Laboratory. Dordrecht: Springer, 2002, pp. 9-20. Disponível em: <https://doi. org/10.1007/0-306-48196-0_3>. Acessado em 14 nov. 2017.

PIERCE, Benjamin. "Introduction to Genetics". In: Genetics: a Conceptual Approach. New York: W. H. Freeman, 2012, pp. 1-14.

Publicado em 04/07/2018. 